\title{
Comparison between primary school children of urban and rural areas for prevalence of uncorrected refractive errors and amblyopia
}

\author{
Singh $\mathbf{P}^{1}$, Agarwal $\mathbf{R}^{2}$, Kashiv $\mathbf{Y}^{3}$, Gupta $S \mathbf{B}^{4}$, Kumar $\mathbf{R}^{5}$ \\ Dr Priti Singh, Associate Professor, Department of Ophthalmology, Dr Rahul Agarwal, Associate Professor, Department \\ of Ophthalmology, Dr Yuri Kashiv, Junior Resident, Department of Ophthalmology, Dr S B Gupta, Professor \& Dean, \\ Dr Rashmi Kumar, Assistant Professor, Department of Ophthalmology. All are affiliated with L N Medical College, \\ Bhopal, MP, India
}

Address for correspondence: Dr Priti Singh, Email: singh_priti2178@yahoo.com

\begin{abstract}
Aims: The present study was planned to evaluate the prevalence of uncorrected refractive errors and the frequency of amblyopia in primary school children, and to compare the findings between rural and urban settings. Material and Method: It was a cross sectional study in which 560 children studying in $1^{\text {st }}$ to $6^{\text {th }}$ standard in age group of 6 to 10 years in primary school of urban and rural area were evaluated for uncorrected refractive errors and amblyopia. All children underwent a preliminalary examination at school level and those who were having refractive errors were further undergone a detail eye check up at ophthalmology OPD of our medical college. Later on the data was analysed statistically. Results: The prevalence of uncorrected refractive errors was found to be $10.35 \%(29 / 280)$ in urban area and $8.57 \%$ (24/280) in rural area. Out of total uncorrected refractive errors, mostly have uncorrected myopia both in urban and rural areas. Conclusion: Difference in prevalence of uncorrected refractive errors and amblyopia was found to be statistically insignificant in both the urban and rural primary school children. ( $p$ value $=0.564$ for uncorrected refractive errors and $\mathrm{p}$ value $=1$ for amblyopia)
\end{abstract}

Keywords: Visual Acuity, Amblyopia, Refractive Error

\section{Introduction}

Uncorrected refractive errors could be as an avoidable condition among various conditions leading to visual disabilities in children. Most of children with uncorrected refractive errors are asymptomatic and hence screening helps in early detection and timely interventions [1-2].

Myopia is the most common refractive error in school going children and high myopia leads to potentially blinding condition such as retinal tear, retinal detachment, macular degeneration, glaucoma and cataract. Other causes include hyperopia and astigmatism that leads to amblyopia [3-5] .

In the school going children amblyopia sets in due to uncorrected refractive errors and this is due to lack of

Manuscript received: $14^{\text {th }}$ Aug 2015

Reviewed: $24^{\text {th }}$ Aug 2015

Author Corrected: $10^{\text {th }}$ Sept 2015

Accepted for Publication: $16^{\text {th }}$ Sept 2015 awareness, education and appropriate interventions [6]. Therefore it is necessary to estimate its prevalence and prescribe appropriate treatment in these children.

Rationale behind this study is to simply know the prevalence of uncorrected refractive error and amblyopia and then facilitating the prophylaxis and treatment of both the condition [7].

It also has positive effects on the psychosocial development of children [8].

Importance of this study is that a large number of children can be screened in a faster, cheaper and more effective way.

We have selected this topic for study because this is concerned with children who are the future of this 
country. Therefore prevention of such debilitating condition is necessary in this age group.

India being a developing country, maximum population residing in urban areas is middle class. Although the parents are educated and aware but these children still suffer from many ocular manifestations. This may be due to frequent usage of modern gadgets.

Aims: Aims of study are:

(1) To study the prevalence of uncorrected refractive errors in primary school children.

(2) To know the frequency of amblyopia in these children (6-10 years).

(3) To compare findings between rural \& urban settings.

\section{Material and Method}

This cross sectional study was conducted among children studying from $1^{\text {st }}$ to $6^{\text {th }}$ standard in the age group 6 to 10 years in the primary school of one urban area (Green Valley, Bhopal) and another school of rural area (Kajlikheda, Bhopal) between July and august of 2013.

Sample size was 560 children (280 from urban settings and 280 from rural settings). All school children were selected as study subjects those who were present in these days. A total of 560 school children were examined.
Informed consent from the parents of students was obtained with the assistance of school heads through their class teachers.

Preliminary examination of school children was done at the respective schools. A short history, including family history about current problems and past problems was recorded.

Instruments used during this study was Snellen's test type in urban area and picture chart in rural area for distant vision keeping it at 6 metres distances from the subjects and near vision was tested with the help of Jaeger's chart keeping the distance of $25-30 \mathrm{~cm}$ from the eyes of the subjects. All students with vision less than $6 / 6$ were considered in our study. Examination of eyelid margins and cilia, conjunctiva, cornea and anterior segment was also done using a torch.

Then children suffered from any visual impairment were selected from both the schools and they were called for further retinoscopic examination and fundus examination to know the type of refractive error or whether this error leads to amblyopia or for its correction.

A short talk was also done after ophthalmic examination with children and their teachers regarding eye health education.

\section{Results}

Out of 280 children in urban areas 29 presented with uncorrected refractive error. In rural areas, out of 280, 24 students were found with uncorrected refractive error and the prevalence of uncorrected refractive error in urban area is $10.35 \%$ and in rural area it is $8.57 \%$. ( Table 1 and Figure $1 \& 2$ )

Table 1: Prevalence of uncorrected refractive error in urban and rural area

\begin{tabular}{|l|l|l|l|l|}
\hline S. No. & Area & $\begin{array}{l}\text { Total no. of students } \\
\text { examined }\end{array}$ & $\begin{array}{l}\text { Students with } \\
\text { refractive error }\end{array}$ & $\begin{array}{l}\text { Prevalence of uncorrected } \\
\text { refractive error }\end{array}$ \\
\hline 1 & Urban & 280 & 29 & $10.35 \%$ \\
\hline 2 & Rural & 280 & 24 & $8.57 \%$ \\
\hline
\end{tabular}

$P$ value $=0.564$ and it is statistically insignificant. 


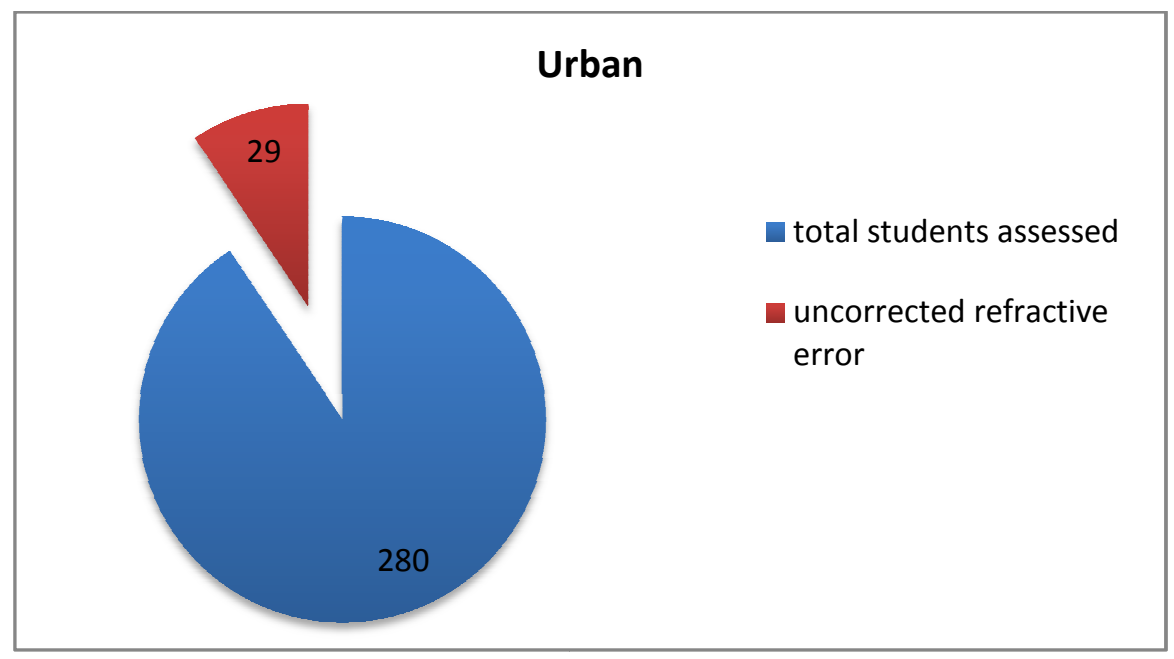

Figure-1: Uncorrected refractive error in urban area

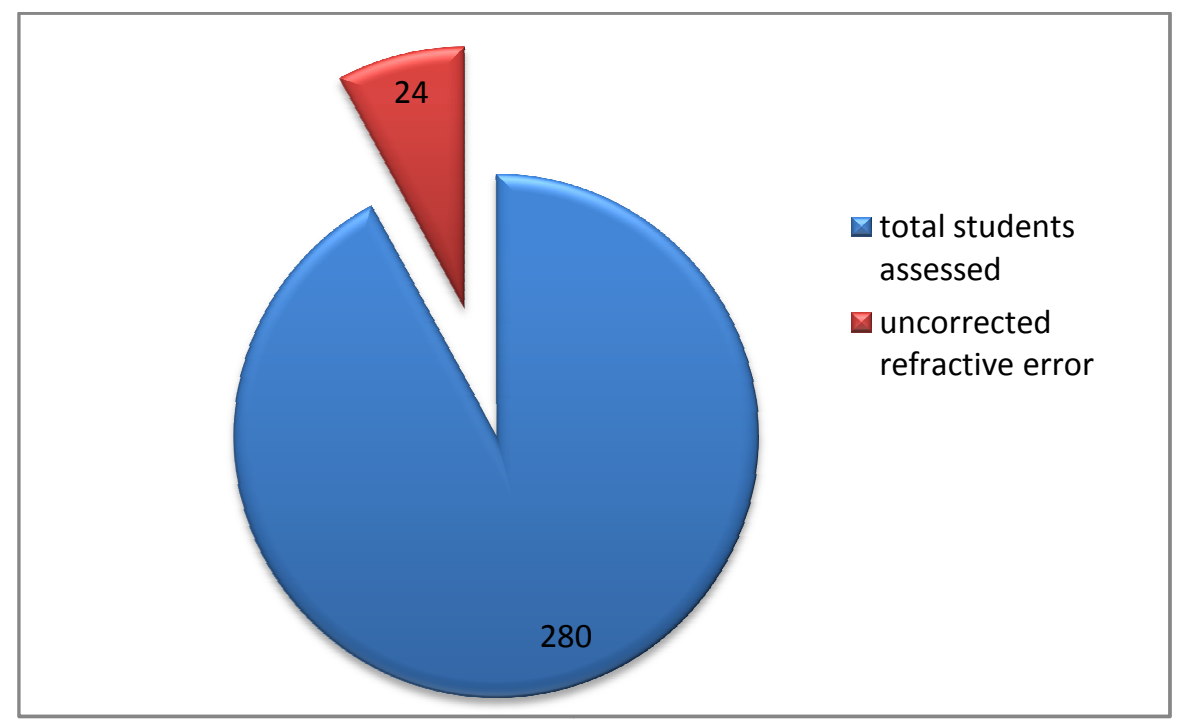

Figure-2: Uncorrected refractive error in rural area

Out of total uncorrected refractive error children both in urban and rural area, mostly ( $55.1 \%$ in urban \& $58.3 \%$ in rural) they have uncorrected myopia.( table $2 \& 3$ )

Table 2: Age- wise distribution of prevalence of uncorrected refractive errors and amblyopia in urban area

\begin{tabular}{|c|c|c|c|c|c|}
\hline \multirow{2}{*}{$\begin{array}{l}\text { Age group } \\
\text { (years) }\end{array}$} & \multirow{2}{*}{$\begin{array}{l}\text { No. of students with } \\
\text { uncorrected refractive } \\
\text { error (prevalence) }\end{array}$} & \multicolumn{3}{|c|}{ Type of uncorrected refractive error } & \multirow[t]{2}{*}{ Amblyopia } \\
\hline & & Myopia & Hyper & Astigmatism & \\
\hline $6-7$ & $6(20.6 \%)$ & 2 & 3 & 1 (SHA) & 1 (Hyper) \\
\hline $7-8$ & $4(13.7 \%)$ & 1 & 2 & $\begin{array}{l}1 \text { (CHA) with } \\
\text { squint }\end{array}$ & 1 (squint) \\
\hline $8-9$ & $8(27.5 \%)$ & 4 & 2 & 2 (CMA) & - \\
\hline $9-10$ & $9(31.03 \%)$ & 7 & 1 & 1 (CMA) & 1(myopia) \\
\hline $10-11$ & $2(3.44 \%)$ & 2 & - & - & - \\
\hline Total & $29(10.35 \%)$ & $16(55.1 \%)$ & $8(27.5 \%)$ & $5(17.24 \%)$ & $3(10.3 \%)$ \\
\hline
\end{tabular}


Table 3: Age- wise distribution of prevalence of uncorrected refractive errors and amblyopia in rural area

\begin{tabular}{|c|c|c|c|c|c|}
\hline \multirow{2}{*}{$\begin{array}{l}\text { Age } \\
\text { group } \\
\text { (yrs) }\end{array}$} & \multirow{2}{*}{$\begin{array}{l}\text { No. of students with } \\
\text { uncorrected refractive error } \\
\text { (prevalence) }\end{array}$} & \multicolumn{3}{|c|}{ Type of uncorrected refractive error } & \multirow[t]{2}{*}{ Amblyopia } \\
\hline & & Myopia & Hyper & Astigmatism & \\
\hline $6-7$ & $2(8.33 \%)$ & - & 2 & - & 1(Hyper) \\
\hline $7-8$ & - & - & - & - & - \\
\hline $8-9$ & - & - & - & - & - \\
\hline $9-10$ & $9(37.5 \%)$ & 5 & 2 & 2(CMA) & 1(CMA) \\
\hline $10-11$ & $13(54.1 \%)$ & 9 & - & $4(\mathrm{CMA})$ & - \\
\hline Total & $24(8.57 \%)$ & $14(58.3 \%)$ & $4(16.6 \%)$ & $6(25 \%)$ & (2) $8.33 \%$ \\
\hline
\end{tabular}

After comparing the prevalence of both uncorrected refractive error and amblyopia in both urban and rural primary school children $\mathrm{p}$ value for uncorrected refractive error $=0.564$ and $\mathrm{P}$ value for amblyopia $=1$ which shows it is statistically insignificant.( figure $3 \& 4$ )

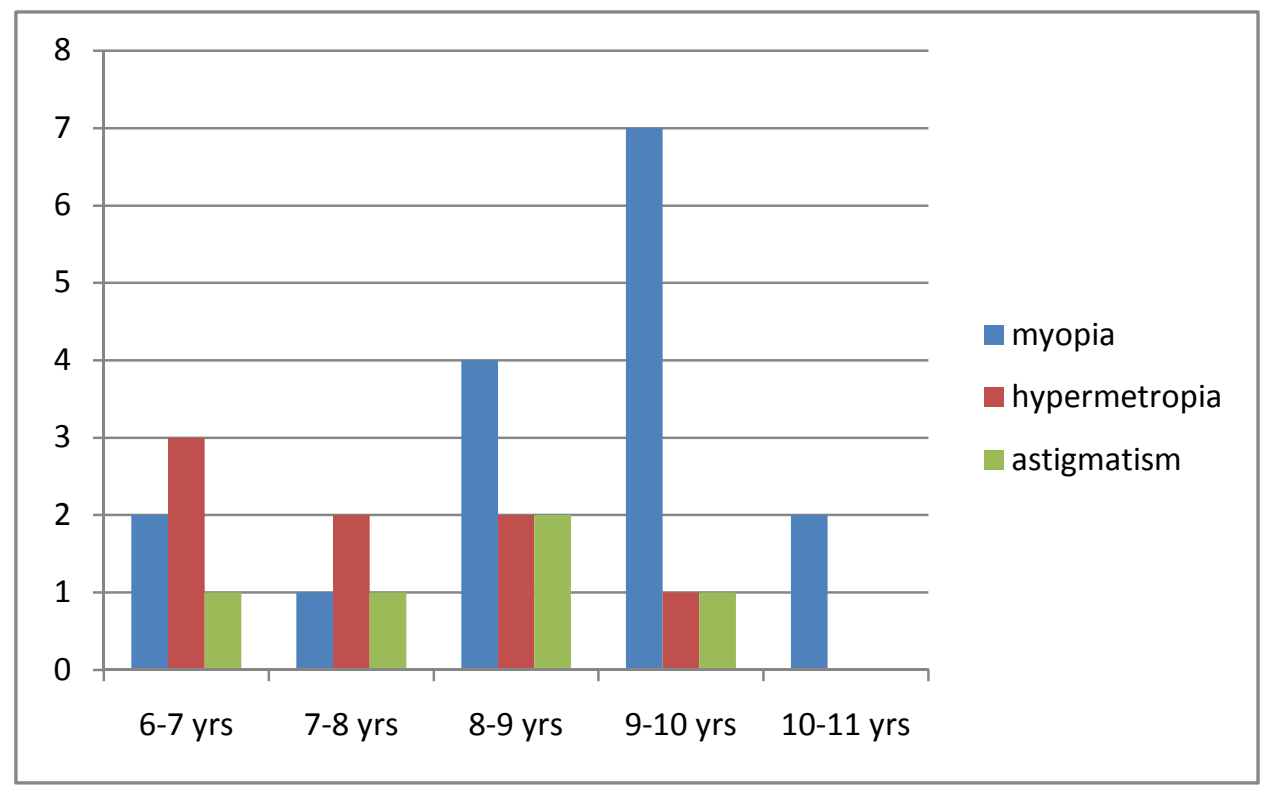

Figure 3: Age wise comparison between types of uncorrected refractive error in urban area.

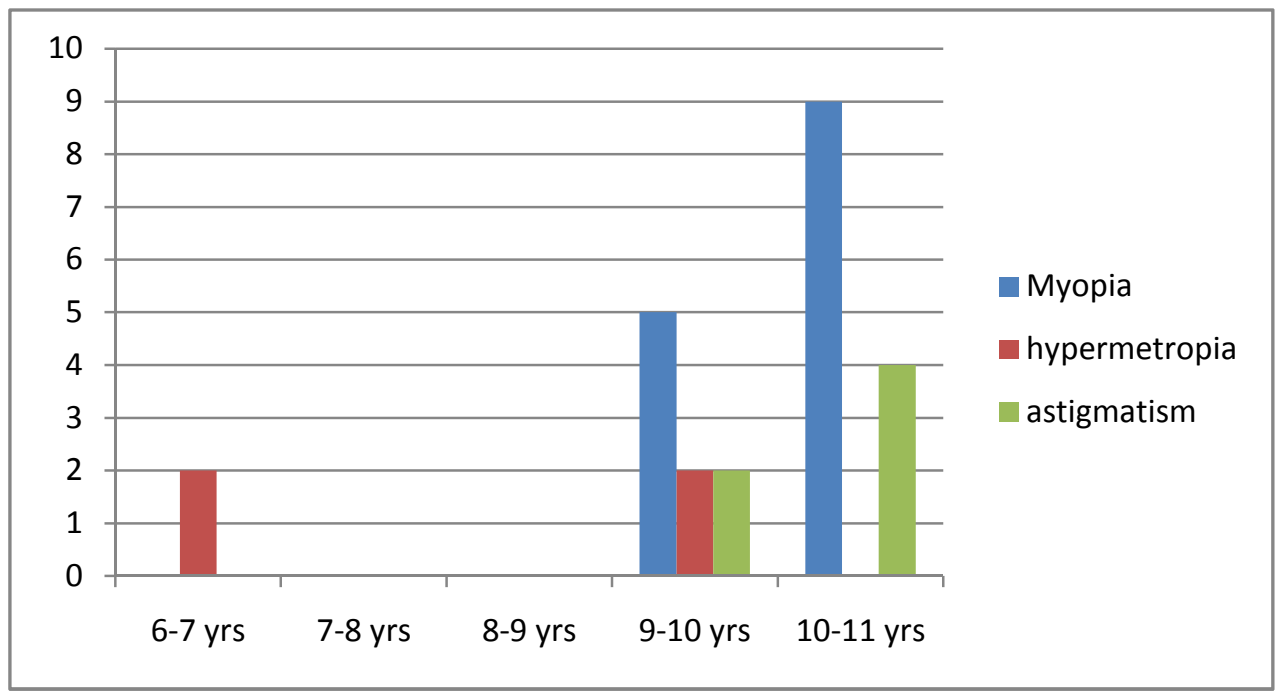

Figure 4: Age wise comparison between types of uncorrected refractive error in rural area. 


\section{Discussion}

Refractive errors are responsible for more than half of the impaired vision in the majority of surveyed population $[9,10]$. They affect a large proportion of the population worldwide, irrespective of age, sex, or ethnic group. They can be easily diagnosed, measured, and corrected and with spectacles and other refractive corrections to obtain normal vision. Unless corrected they cause low vision and even blindness [9,11]. The prevalence of refractive errors varies according to race and geographic location $[9,10]$, gender $[10,11]$, age [10,11], educational level, amount of near work [12] and parental education [12].

In current study prevalence of uncorrected refractive error is $10.35 \%$ in urban areas and $8.57 \%$ in rural children which differs from the results shown by A study by H.V. Desai Eye Hospital, Pune, India (2009), the prevalence of uncorrected refractive error in urban and rural children was $5.46 \%$ and $2.63 \%$ respectively.

In this study myopia is the main type of uncorrected refractive error which corresponds with the study In Southern China, minggaug he et al found (2002-2003) refractive error was the cause of $94.9 \%$ of reduced vision and myopia was the main cause and amblyopia in $1.9 \%$. In a study, the prevalence of refractive error and impairment in school children in Gombak District, a suburban area near Kuala Lumpur City; they concluded that visual impairment was overwhelming caused by myopia.

In this study the prevalence of amblyopia in urban is $10.3 \%$ and in rural is $8.3 \%$ which has near about similar results with A study by H.V. Desai Eye Hospital, Pune, India (2009) the prevalence of amblyopia was $0.8 \%$ in urban and $0.2 \%$ in rural children.

It was observed during the study that urban area has higher risk of developing uncorrected refractive errors due to overuse of modern gadgets. Although their parents are aware but still they are presented with these ocular manifestations and Sethi et al and Matta et al also observed that urban children had higher risk of developing refractive error [13,14]. The prevalence and severity of myopia were significantly higher in children of urban schools compared to those of rural schools in Taiwan [15].
The aim of present study was to evaluate and compare the prevalence of uncorrected refractive error and amblyopia in urban and rural settings.

Difference in prevalence of uncorrected refractive errors and amblyopia is statistically insignificant. ( $p$ value $=0.564$ for uncorrected refractive errors and $\mathrm{p}$ value $=1$ for amblyopia)

\section{Funding: Nil \\ Conflict of interest: None. \\ Permission of IRB: Yes}

\section{Reference}

1. Resnikoff S, Pascolini D, Mariotti SP, Pokharel GP. Global magnitude of visual impairment caused by uncorrected refractive errors in 2004.Bull World Health Organ. 2008 Jan;86(1):63-70.

2. . World Health Organization. Elimination of avoidable visual disability due to refractive error Report of an informal planning meeting WHO/PBL/00.79 pp: 6-10.

3. Kempen JH, Mitchell P, Lee KE, Tielsch JM, Broman AT, Taylor HR, Ikram MK, Congdon NG, O'Colmain BJ; Eye Diseases Prevalence Research Group. The prevalence of refractive errors among adults in the United States, Western Europe, and Australia. Arch Ophthalmol. 2004 Apr;122(4):495-505.

4.Tong L, Saw SM, Lin Y, Chia KS, Koh D, Tan D. Incidence and progression of astigmatism in Singaporea $\mathrm{n}$ children. Invest Ophthalmol Vis

Sci. 2004 Nov;45(11):3914-8.

5. Goh PP, Abqariyah Y, Pokharel GP, Ellwein LB. Refractive error and visual impairment in school age children in Gombak District, Malaysia.

Ophthalmology. 2005 Apr;112(4):678-85.

6. Khurana A K , Khurana B .Optics and Refraction .In: Khurana A K , editor. Comprehensive ophthalmology, $5^{\text {th }}$ ed. New Delhi:New age international (p)limited publishers.;2012.p.478-479.

7. Sihota $R$, Tandon R . Refractive errors of the eye . In: Sihota R, Tandon R, editors. Parson's Diseases Of The Eye , $21^{\text {st }}$ ed. New Delhi: Elsevier ; 2011.p.79.

\section{Conclusion}


8. Koklanis K, Abel LA, Aroni R. Psychosocial impact of amblyopia and its treatment: a multidisciplinary study. Clin Experiment Ophthalmol. 2006

Nov;34(8):743-50.

9. He M, Zeng J, Liu Y, Xu J, Pokharel GP, Ellwein LB. Refractive error and visual impairment in urban children in southern china. Invest Ophthalmol Vis Sci. 2004 Mar;45(3):793-9.

10. Goh PP, Abqariyah Y, Pokharel GP, Ellwein LB. Refractive error and visual impairment in school age children in Gombak District, Malaysia.

Ophthalmology. 2005 Apr;112(4):678-85.

\section{Zhao J, Mao J, Luo R, Li F, Munoz SR, Ellwein} LB. The progression of refractive error in school age children : Shunyi district, China. Am J Ophthalmol. 2002 Nov;134(5):735-43.
12. Wedner SH, Ross DA, Todd J, Anemona A, Balira R, Foster A. Myopia in secondary school student in Mwanza City, Tanzania: the need for a national screening programme. Br J Ophthalmol. 2002 Nov;86(11):1200-6.

13. Sethi S, Kartha GP. Prevalence of refractive errors among school children of Ahmedabad city. Ind Journ Com Med 2000;25:181-3.

14. Matta S, Matta P, Gupta V, Dev A. Refractive errors among adolescents attending Ophthalmic OPD; Ind Joun Comm Medicine. 2006-04 - 2005-06; 31(2).

15. Lin LL, Shih YF, Hsiao CK, Chen CJ, Lee LA, Hung PT. Epidemiologic study of the prevalence and severity of of myopia among schoolchildren in Taiwan in 2000. J Formos Med Assoc. 2001 Oct;100(10):684-91.

\section{How to cite this article?}

Singh P, Agarwal R, Kashiv Y, Gupta S B, Kumar R. Comparison between primary school children of urban and rural areas for prevalence of uncorrected refractive errors and amblyopia. Int J Med Res Rev 2015;3(8):871-876. doi: 10.17511/ijmrr.2015.i8.164. 